\title{
Ruthenium Dioxide Nanoparticles in Ionic Liquids: Synthesis, Characterization and Catalytic Properties in Hydrogenation of Olefins and Arenes
}

\author{
Liane M. Rossi ${ }^{*, a, \#, ~ J a i r t o n ~ D u p o n t ~}{ }^{a}$, Giovanna Machado $^{a}$, Paulo F. P. Fichtner $^{b}$, Claúdio Radtke $^{c}$, \\ Israel J. R. Baumvol ${ }^{c}$ and Sergio R. Teixeira ${ }^{c}$ \\ ${ }^{a}$ Instituto de Química, Universidade Federal do Rio Grande do Sul, CP 1503, 91501-70 Porto Alegre - RS, Brazil \\ ${ }^{b}$ Departamento de Metalurgia, Universidade Federal do Rio Grande do Sul, 90035-190 Porto Alegre - RS, Brazil \\ ${ }^{c}$ Instituto de Física, Universidade Federal do Rio Grande do Sul, CP 15051, 91501-970 Porto Alegre - RS, Brazil
}

\begin{abstract}
A reação de $\mathrm{NaBH}_{4}$ com $\mathrm{RuCl}_{3}$ dissolvido no líquido iônico 1-n-butil-3-metilimidazólio hexafluorfosfato (BMI.PF ${ }_{6}$ é um método simples e reprodutível para a síntese de nanopartículas de $\mathrm{RuO}_{2}$ estáveis com distribuição estreita e diâmetro da partícula entre 2-3 nm. As nanopartículas de $\mathrm{RuO}_{2}$ foram caracterizadas por XRD, XPS, EDS e TEM. Estas nanopartículas mostraram alta atividade catalítica tanto na catálise heterogênea quanto na hidrogenação bifásica líquido-líquido de olefinas e arenos sob condições moderadas de reação. Experimentos de envenenamento com $\mathrm{Hg}(0)$ e $\mathrm{CS}_{2}$, e análises de XRD e TEM de partículas isoladas após a catálise indicaram a formação de nanopartículas de $\mathrm{Ru}(0)$. As nanopartículas podem ser reutilizadas em condições de catálise heterogênea até 10 vezes na hidrogenação de 1-hexeno rendendo um número total de ciclos catalíticos de 175.000 para átomos de Ru expostos.
\end{abstract}

The reaction of $\mathrm{NaBH}_{4}$ with $\mathrm{RuCl}_{3}$ dissolved in 1-n-butyl-3-methylimidazolium hexafluorophosphate $\left({\mathrm{BMI} . \mathrm{PF}_{6}}_{6}\right)$ ionic liquid is a simple and reproducible method for the synthesis of stable $\mathrm{RuO}_{2}$ nanoparticles with a narrow size distribution within $2-3 \mathrm{~nm}$. $\mathrm{RuO}_{2}$ nanoparticles were characterized by XRD, XPS, EDS and TEM. These nanoparticles showed high catalytic activity either in the solventless or liquid-liquid biphasic hydrogenation of olefins and arenes under mild reaction conditions. $\mathrm{Hg}(0)$ and $\mathrm{CS}_{2}$ poisoning experiments and XRD and TEM analysis of particles isolated after catalysis indicated the formation of $\mathrm{Ru}(0)$ nanoparticles. The nanoparticles could be re-used in solventless conditions up to 10 times in the hydrogenation of 1-hexene yielding a total turnover number for exposed $\mathrm{Ru}$ atoms of 175,000 .

Keywords: ruthenium dioxide, nanoparticles, ionic liquids, hydrogenation

\section{Introduction}

Among the various transition-metal oxides, $\mathrm{RuO}_{2}$ is one of the most promising materials due to its excellent diffusion barrier properties, high thermal stability and low temperature resistivity. ${ }^{1}$ These materials have several potential applications encompassing large-scale integrated circuits, electrochemical capacitors, electrodes, gas sensors, and catalysis. ${ }^{2,3}$ Nanometric $\mathrm{RuO}_{2}$ confined in a zeolitic framework was recently reported as an efficient catalyst for alcohol oxidation under mild aerobic

* e-mail: 1rossi@iq.usp.br

"Present address: Instituto de Química, Universidade de São Paulo, 05508-900 São Paulo - SP - Brazil. conditions. ${ }^{3}$ It is therefore of great interest to develop more efficient and reliable methods for the generation of $\mathrm{RuO}_{2}$ nanoparticles $(<100 \mathrm{~nm})$. In this context, the sol-gel process is one of the most common used methods for the generation of nano-structured materials compared with classical methods such as co-precipitation or high temperature fusion. ${ }^{4}$ On the other hand, transition-metal stable nanoparticles with controlled size and composition can be obtained by the reduction or oxidation of metal compounds in the presence of protective agents such as surfactants, polymers, quaternary ammonium salts, polyoxoanions or organic ligands to avoid particle agglomeration. ${ }^{5}$ For example, nanosized $\mathrm{PtO}_{2}$ has been easily prepared by hydrolysis/condensation of $\mathrm{Pt}(\mathrm{IV})$ compounds under basic conditions in the presence of carbo- or sulfobetaines. ${ }^{6}$ 
We have recently reported that $\mathrm{Ir}, \mathrm{Rh}$ and $\mathrm{Pt}$ nanoparticles of 2-3 $\mathrm{nm}$ diameter with a narrow size distribution can be synthesized straightforwardly using a one-component liquid phase, namely 1-n-butyl-3methylimidazolium hexafluorophosphate (BMI.PF ${ }_{6}$ ) ionic liquid, ${ }^{7}$ by reduction with molecular hydrogen of the corresponding metal complexes ${ }^{8}$ or by controlled decomposition of $\mathrm{Pt}(0)$ organometallic compounds, ${ }^{9}$ under mild reaction conditions. Therefore these liquids could be used for the generation of nanoscale $\mathrm{RuO}_{2}$ particles. We report herein that the reaction of $\mathrm{RuCl}_{3}$ with $\mathrm{NaBH}_{4}{ }^{10}$ in BMI.PF ${ }_{6}$ ionic liquid yields ruthenium oxide nanoparticles with $2-3 \mathrm{~nm}$ in diameter. The catalytic properties of ruthenium oxide nanoparticles were tested in the solventless or two-phase hydrogenation of olefins and arenes under mild reaction conditions (4 atm of $\mathrm{H}_{2}$ and $\left.75^{\circ} \mathrm{C}\right)$.

\section{Experimental}

\section{Materials and instrumentation}

Anhydrous $\mathrm{RuCl}_{3}$ was purchased from Aldrich Chem.Co. 1-n-butyl-3-methylimidazolium hexafluorophosphate (BMI.PF ${ }_{6}$ ) and 1-n-butyl-3-methylimidazolium

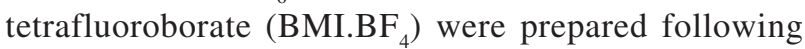
previously reported procedures. ${ }^{11}$ The absence of $\mathrm{Cl}^{-}$was verified by an $\mathrm{Ag}^{+}$test and the water content $(<0.1 \% \mathrm{v} / \mathrm{v})$ was checked by cyclic voltammetry of an authentic sample and after the addition of water. ${ }^{12}$ Olefins were distilled prior to use in hydrogenation reactions. All manipulations were carried out using Schlenk techniques. Gas chromatography was performed in a Shimatzu GC 14B, equipped with a 30 meter capillary column with a dimethylpolysiloxane stationary phase, using the following parameters: initial temperature: $50{ }^{\circ} \mathrm{C}$, initial time: $5 \mathrm{~min}$, ramp: $10^{\circ} \mathrm{C} / \mathrm{min}$, final temperature: $250{ }^{\circ} \mathrm{C}$, final time: $5 \mathrm{~min}$, injector temperature: $250{ }^{\circ} \mathrm{C}$, detector temperature: $250{ }^{\circ} \mathrm{C}$, injection volume: $2 \mu \mathrm{L}$.

\section{Transmission Electron Microscopy measurements}

Transmission electron microscopy (TEM) micrographs were taken on a JEM-2010 microscope operating at an accelerating voltage of $200 \mathrm{kV}$. Samples for TEM observations were prepared in two different ways: by placing a drop of a 2-propanol metal nanoparticle solution on a holey carbon grid or by placing a thin film of the ionic liquid containing the ruthenium nanoparticles in a holey carbon grid. The metal particle size distribution was estimated from the measurement of about 200 particles, assuming spherical shape, found in an arbitrary chosen area in enlarged micrographs.

\section{$X$-ray Diffraction measurements}

$\mathrm{X}$-ray diffraction $(\mathrm{XRD})$ patterns were recorded on a Philips X'PERT MRD X-ray diffractometer equipped with a curved graphite crystal. The diffraction data were collected at room temperature in a Bragg-Brentano $\theta-2 \theta$ geometry. The equipment was operated at $40 \mathrm{kV}$ and $40 \mathrm{~mA}$ with scan range between $20^{\circ}$ to $100^{\circ}$. Samples analyzed under oxygen-free conditions were prepared in a glovebox and covered with Kapton Tape. Simulations of the measured spectra were obtained with a pseudo-Voigt profile using the FULLPROF code. ${ }^{13}$

\section{X-ray Photoelectron Spectroscopy measuraments}

The XPS was performed using $\operatorname{MgK} \alpha$ radiation ( $\mathrm{h} v=$ $1253.6 \mathrm{eV}$ ). High-resolution scans were recorded with a pass energy of $15 \mathrm{eV}$, an angular acceptance of $\pm 4^{\circ}$ and an entrance slit of $2 \mathrm{~mm} \emptyset$ for an Omicron EA 125 concentric hemispheric analyzer. The detection angle $\theta$ of the photoelectrons with respect to the normal to the sample surface (takeoff angle) was varied from $25^{\circ}$ (bulk sensitive mode) to $70^{\circ}$ (surfacesensitive mode). Samples for analysis were prepared by placing the $\mathrm{RuO}_{2}$ on a carbon conducting tape.

\section{Preparation of ruthenium oxide nanoparticles}

In a Schlenk tube, $0.062 \mathrm{~g}(0.3 \mathrm{mmol})$ of $\mathrm{RuCl}_{3}$ was dissolved in $3 \mathrm{~mL}$ of 1-n-butyl-3-methylimidazolium hexafluorophosphate BMI.PF ${ }_{6}$ by heating $\left(50-60^{\circ} \mathrm{C}\right)$ and stirring under argon. The brown solution was cooled to room temperature and an excess of solid $\mathrm{NaBH}_{4}(0.1 \mathrm{~g})$ was added. The suspension was stirred for $2 \mathrm{~h}$ and then the nanoparticles were isolated as a black powder by centrifugation in acetone. The workup procedure consisted of washing the powder obtained with acetone $(2 \times 5 \mathrm{~mL})$, water $(5 \times 5 \mathrm{~mL})$ and acetone $(2 \times 5 \mathrm{~mL})$ followed by centrifugation at $3500 \mathrm{rpm}$ over $5 \mathrm{~min}$ was performed without avoiding oxygen atmosphere. The powder isolated was dried under reduced pressure.

\section{Hydrogenation experiments}

The catalytic reactions were carried out in a FischerPorter reactor connected to a $\mathrm{H}_{2}$ reservoir. In a typical experiment, $\mathrm{RuO}_{2}$ nanoparticles $(3 \mathrm{mg}, 0.0225 \mathrm{mmol}$ ) and $15 \mathrm{mmol}$ of substrate are added to the reactor under an inert atmosphere. In biphasic experiments, the $\mathrm{RuO}_{2}$ 
nanoparticles are dispersed in $1 \mathrm{~mL}$ of room temperature ionic liquid (BMI.PF 6 or $\mathrm{BMI}_{\mathrm{B}} \mathrm{BF}_{4}$ ) prior to the addition of the substrate. The reactor is submitted to vacuum, placed in an oil bath at $75^{\circ} \mathrm{C}$ under stirring (700 rpm) and connected to the hydrogen gas unit. The reaction is initiated by the gas admission at $4 \mathrm{~atm}$ (constant). The reaction is monitored by the fall in hydrogen pressure in the $\mathrm{H}_{2}$ reservoir as a function of time. $\mathrm{H}_{2}$ uptake was measured in 1 min intervals with a Huba Control pressure transducer interfaced via a Novus Field Logger converter to a computer. The pressure versus time data are collected by the FieldChart Novus Software, stored as a data file and exported to a MicroCal Origin 5.0 for hydrogenation rate calculations. The products are separated by decantation of the nanoparticles and the organic phase analyzed by GC and GC-MS.

\section{Catalyst lifetime experiments}

The catalyst lifetime experiments were performed as for the hydrogenation experiments, except for a catalyst to substrate molar ratio of 1/6667 for each charge. In a typical experiment, $\mathrm{RuO}_{2}(2 \mathrm{mg}, 0.015 \mathrm{mmol})$ and 1-hexene $(8.4 \mathrm{~g}, 100 \mathrm{mmol})$ are added to the Fischer-Porter reactor under an inert atmosphere. In biphasic experiments, $0.5 \mathrm{~mL}$ of room temperature ionic liquid (BMI.PF ${ }_{6}$ ) is added prior to the addition of the substrate. The reactor is submitted to vacuum, placed in an oil bath at $75^{\circ} \mathrm{C}$ under stirring (700 rpm) and connected to the hydrogen gas unit. The reaction is initiated by gas admission at 4 atm (constant). The reaction is monitored by the fall in hydrogen pressure in the $\mathrm{H}_{2}$ reservoir, measured via a computer interfaced pressure transducer, as a function of time. At the end of the reaction (when the $\mathrm{H}_{2}$ uptake has stopped), the reactor is cooled to room temperature and depressurized. An aliquot of the product is collected, under an inert atmosphere, and analyzed by GC. If all the 1-hexene is converted to hexane the maximum turnover had been attained. The remaining amount of hexane is evaporated in vacuum and an additional $8.4 \mathrm{~g}$ of 1 -hexene $(100 \mathrm{mmol})$ is added to the reactor, which is evacuated and reattached to the hydrogen unit. The pressure is reestablished to 4 atm of $\mathrm{H}_{2}$ (constant) and a new recording of $\mathrm{H}_{2}$ uptake $v s$. time starts. The same procedure is repeated until a significant loss of activity is observed. In each experiment 6667 maximum turnovers are possible.

\section{$H g(0)$ poisoning test ${ }^{14}$}

The catalytic reactions were carried out in the same hydrogenation standard conditions $\left(\mathrm{RuO}_{2}\right.$ nanoparticles (3 mg, $0.0225 \mathrm{mmol})$ and $1.26 \mathrm{~g}$ (15 mmol) of 1-hexene), except for the addition of elemental $\mathrm{Hg}$ (1.4 g, 300 equiv.) to the reaction mixture at $50 \%$ of conversion of 1 -hexene to hexane. The reaction is monitored by the fall in hydrogen pressure in the $\mathrm{H}_{2}$ reservoir as a function of time before and after addition of $\mathrm{Hg}$. The products are separated by decantation of the nanoparticles and the organic phase is analyzed by GC and GC-MS.

\section{$\mathrm{CS}_{2}$ poisoning test}

The catalytic reactions were carried out in the same hydrogenation standard conditions $\left(\mathrm{RuO}_{2}(6 \mathrm{mg}, 0.045\right.$ $\mathrm{mmol})$ and $1.26 \mathrm{~g}(15 \mathrm{mmol})$ of 1-hexene), except for the addition of 0.5 equivalents of $\mathrm{CS}_{2}(1.7 \mathrm{mg})$ dissolved in an additional $1.26 \mathrm{~g}$ of 1 -hexene to the reaction mixture at $50 \%$ of conversion of 1 -hexene to hexane. The reaction is monitored by the fall in hydrogen pressure in the $\mathrm{H}_{2}$ reservoir as a function of time before and after addition of $\mathrm{CS}_{2}$. The products are separated by decantation of the nanoparticles and the organic phase is analyzed by GC and GC-MS.

\section{Results and Discussion}

\section{$\mathrm{RuO}_{2}$ nanoparticles preparation and characterization}

The addition of an excess of $\mathrm{NaBH}_{4}$ to a dispersion of

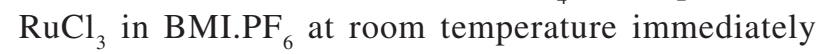
yielded a black solution. A black powder was isolated by centrifugation and analyzed by Transmission Electron Microscopy (TEM), X-ray Diffraction (XRD), Energy Dispersive Spectroscopy (EDS) and X-ray Photon-electron Spectroscopy (XPS). Nanoparticles size and size distribution were obtained from TEM photographs (Figure 1A). The particle size distribution was estimated from the measurement of the diameter of avg. 250 particles found in arbitrary chosen area in enlarged micrographs. Figure 1B shows the particle size distribution with an average diameter of $2.4 \pm 0.5 \mathrm{~nm}$.

The electron and X-ray diffraction patterns could be adjusted to the predicted lines of the $\mathrm{RuO}_{2}$ orthorhombic structure (Figure 2 and Figure 3). Lattice fringes images (Figure 1C) and diffraction ring patterns from Selected Area Diffraction (SAD) confirm the crystalline nature of the particles.

The simulations of Bragg reflections were performed with a pseudo-Voigt profile using the FULLPROF code based on the cell parameters of $\mathrm{RuO}_{2}$. The result of simulation, continuous line in Figure 3 , is in good agreement with the measured spectrum. The most representative reflections of the $\mathrm{RuO}_{2}$ were indexed as 
orthorhombic and the latticet parameters were $\mathrm{a}=4.5786$, $\mathrm{b}=4.5651$ and $\mathrm{c}=3.1426, \alpha=\beta=90$ and $\gamma=89.9474$. The Bragg reflections at $27.56^{\circ}, 34.59^{\circ}, 34.61^{\circ}, 39.33^{\circ}, 39.97^{\circ}$, $53.38^{\circ}, 53.42^{\circ}, 56.89^{\circ}, 58.71^{\circ}, 66.05^{\circ}, 68.27^{\circ}$ and $72.97^{\circ}$ correspond to the indexed planes of the crystals of $\mathrm{RuO}_{2}$
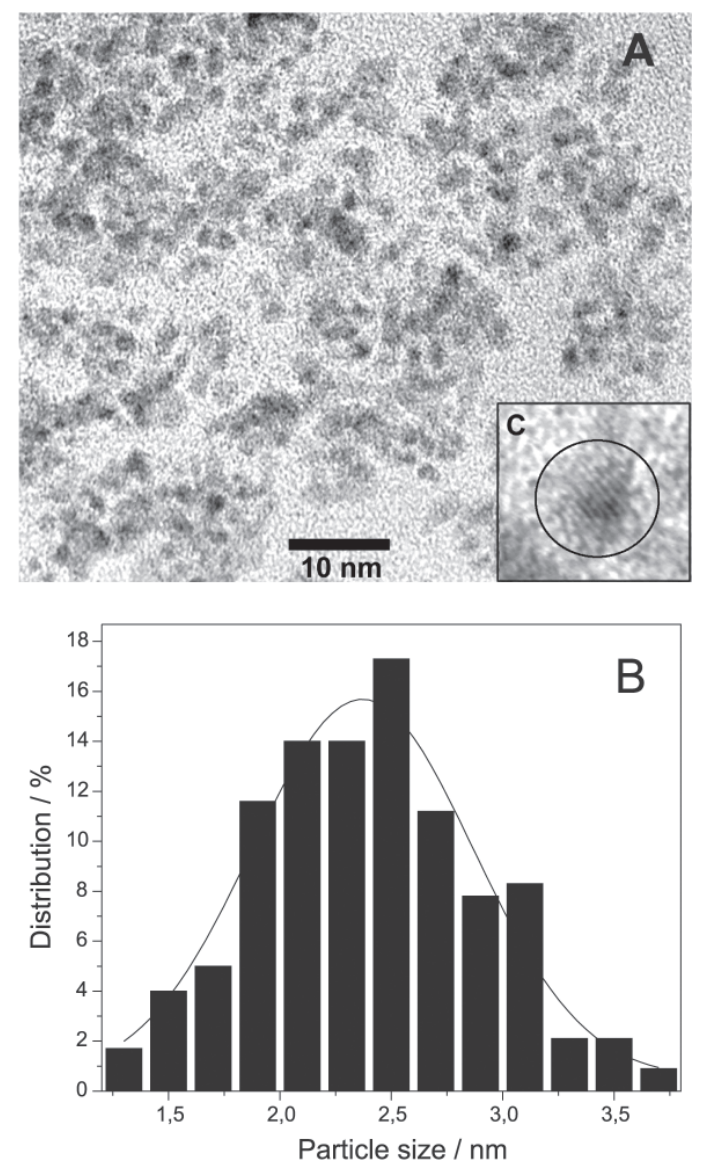

Figure 1. (A) Transmission electron micrograph of $\mathrm{RuO}_{2}$ nanoparticles with $400 \mathrm{Kx}$ of magnification; (B) Histogram illustrating the particle size distribution; (C) Lattice image of $\mathrm{RuO}_{2}$ nanoparticle showing its crystalline structure ( $600 \mathrm{Kx}$ of magnification).

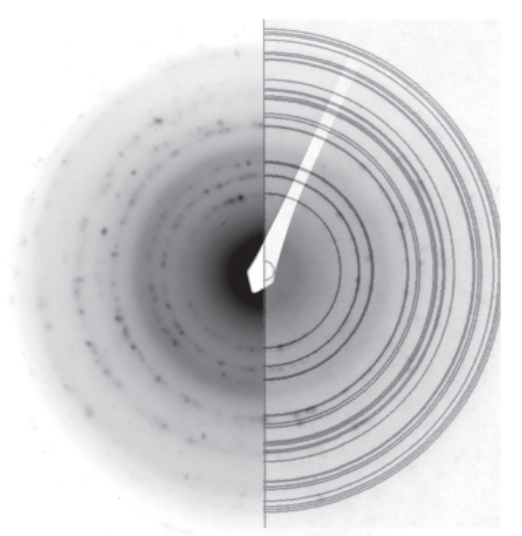

Figure 2. Electron Diffraction Rings of the $\mathrm{RuO}_{2}$ nanoparticles measured by SAD (experimental in the left side and theoretical in the right).

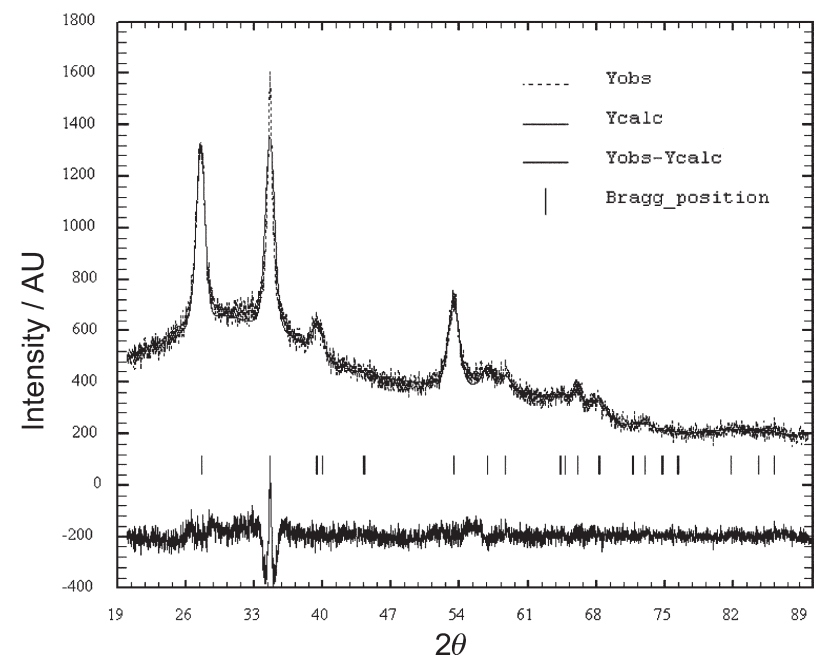

Figure 3. $\mathrm{X}$-ray diffraction pattern of $\mathrm{RuO}_{2}$ nanoparticles prepared by reaction of $\mathrm{NaBH}_{4}$ with $\mathrm{RuCl}_{3}$ in $\mathrm{BMI} . \mathrm{PF}_{6}$.

(110), (101), (011), (200), (111), (211), (121), (220), (002), (112), (301) and (202).

The surface composition of the material was also analyzed using X-ray photoelectron spectroscopy (XPS). Figure 4 displays a survey surface scan of nanoparticles prepared by reaction of $\mathrm{NaBH}_{4}$ with $\mathrm{RuCl}_{3}$ in BMI.PF . Only the peaks corresponding to carbon (support), ruthenium and oxygen were observed. Note that the $\mathrm{Ru}$ $3 d_{3 / 2}$ component appears more intense due to the superposition with the $\mathrm{C} 1 \mathrm{~s}$ signal. The formation of the $\mathrm{RuO}_{2}$ nanoparticles probably proceeds through the reduction of $\mathrm{Ru}(\mathrm{III})$ chloride to ruthenium poly-hydride species that are easily oxidized in air. ${ }^{15}$

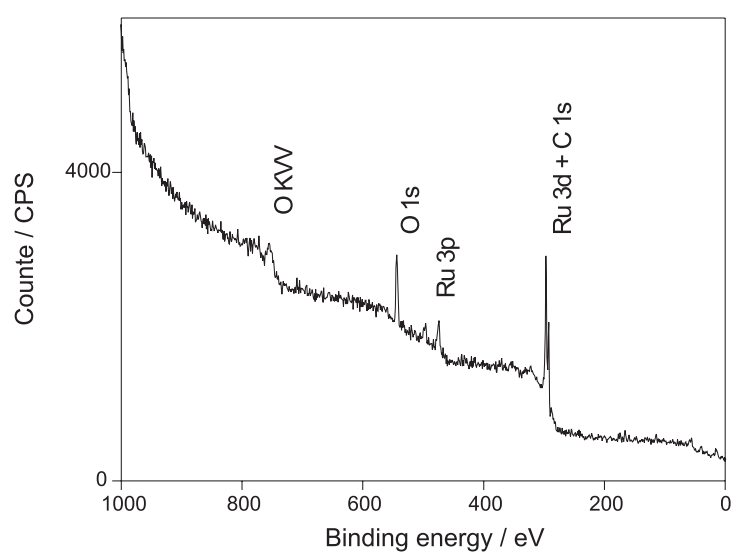

Figure 4. XPS surface survey of the $\mathrm{RuO}_{2}$ prepared by the reaction of $\mathrm{NaBH}_{4}$ with $\mathrm{RuCl}_{3}$ in BMI.PF 6 ionic liquid.

Hydrogenation of olefins and arenes using $\mathrm{RuO}_{2}$ nanoparticles prepared in ionic liquid

The isolated $\mathrm{RuO}_{2}$ nanoparticles were used directly for heterogeneous catalysis (solventless) or re-immobilized 
Table 1. Hydrogenation ${ }^{\mathrm{a}}$ of olefins and arenes by $\mathrm{RuO}_{2}$ nanoparticles pre-catalyst

\begin{tabular}{lllllll}
\hline Entry & Substrate & Product(s) & Medium & Time $(\mathrm{h})$ & Conv. $^{\mathrm{b}}(\%)$ & TOF $^{\mathrm{c}}\left(\mathrm{h}^{-1}\right)$ \\
\hline 1 & 1-hexene & hexane & None & 0.2 & 99 & 3300 \\
2 & 1-hexene & hexane & BMI.BF & 3.0 & 98 & 218 \\
3 & 1-hexene & hexane & BMI.PF $_{6}$ & 1.2 & $>99$ & 556 \\
4 & cyclohexene & cyclohexane & None & 0.4 & $>99$ & 1668 \\
5 & cyclohexene & cyclohexane & BMI.PF & 3.0 & $>99$ & 222 \\
6 & 1-methyl-1-cyclohexene & methylcyclohexane & None & 1.8 & $>99$ & 370 \\
7 & 1-methyl-1-cyclohexene & methylcyclohexane & BMI.PF & 5.4 & 97 & 120 \\
8 & 2,3-dimethyl-2-butene & 2,3-dimethylbutane & None & 0.5 & $>99$ & 1334 \\
9 & 2,3-dimethyl-2-butene & 2,3-dimethylbutane & BMI.PF & 20.0 & 89 & 30 \\
10 & benzene & cyclohexane & None & 2.5 & $>99$ & 267 \\
11 & benzene & cyclohexane & BMI.BF & 24.0 & 3 & $<1$ \\
12 & benzene & methylcyclohexane & BMI.PF & 15.0 & 97 & 43 \\
13 & toluene & 1,4-dimethylcyclohexane & & 58 & 50 \\
14 & p-xylene & None & 13.0 & 17.0 & 64 & 25
\end{tabular}

a Conditions: catalyst/substrate ratio $=1 / 667$, temperature $=75^{\circ} \mathrm{C}$, hydrogen pressure $=4 \mathrm{~atm} ;{ }^{\mathrm{b}}$ Measured by GC; ${ }^{\mathrm{c}}$ Catalytic turnover frequency: moles of substrate transformed per mole of catalyst per hour. ${ }^{\mathrm{d}} \mathrm{cis} / \mathrm{trans}=2.1$.

in BMI.PF ${ }_{6}$ for use in liquid-liquid biphasic catalysis. The hydrogenation of 1-hexene catalyzed by $\mathrm{RuO}_{2}$ nanoparticles was performed at $75{ }^{\circ} \mathrm{C}$ and 4 atm (constant pressure) of $\mathrm{H}_{2}$ (Table 1, entries 1-3). As a control experiment, the hydrogenation of 1-hexene was performed, in the same experimental conditions, using $\mathrm{RuCl}_{3}$ as catalyst instead of the nanoparticles and no hydrogen consumption was observed even after $3 \mathrm{~h}$ of reaction. In solventless conditions, the conversion to hexane was complete within 12 min corresponding to a catalytic turnover frequency of $3300 \mathrm{~h}^{-1}$. In biphasic catalysis carried out with the addition of $1 \mathrm{~mL}$ of BMI.PF ${ }_{6}$ or ${\mathrm{BMI} . \mathrm{BF}_{4}}_{4}$ ionic liquids to the nanoparticles, the reaction time increased resulting in catalytic turnover frequencies of 556

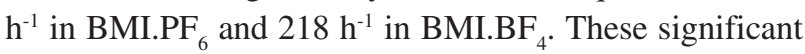
differences in the catalytic activity can be attributed to the decreasing solubility of the olefin in the ionic phase (olefins are usually 2-3 times more soluble in the BMI.PF ionic liquid than in the BMI.BF ${ }_{4}$ analog). ${ }^{7}$ Upon standing, a black precipitate of nanoparticles could be separated from the hydrogenated product and re-used for up to six successive recycles, retaining nearly all of the original reactivity. Also in the biphasic systems, the hydrogenated product could be isolated by simple decantation and the catalyst remaining immobilized in the ionic liquid phase re-used for successive recycles. The catalytic performance of the $\mathrm{RuO}_{2}$ nanoparticles in the solventless or biphasic hydrogenation of other olefins and arenes are summarized in Table 1.

The catalytic activity showed the expected trend for hydrogenation of the series of substrates investigated, in that the highest turnover frequency was observed for the non-aromatic and less substituted olefin. Moreover, the catalyst was active in the hydrogenation of arenes such as benzene to cyclohexane with a turnover frequency of $267 \mathrm{~h}^{-1}$ (Table 1, entry 10). ${ }^{16}$ The nanoparticles present a remarkable effectiveness for the hydrogenation of tetra-substituted double bonds (Table 1, entries 8 and 9). In comparison to the solventless system, the biphasic catalysis has proven to be less active probably due to the low solubility of the substrates in the ionic liquid catalyst-containing layer. ${ }^{8}$

Characterization of the material isolated after hydrogenation reactions by TEM, electron diffraction and $X$-ray diffraction

After hydrogenation of 1-hexene by $\mathrm{RuO}_{2}$ following standard conditions described in the experimental section, a black precipitated material was isolated under an inert atmosphere and examined by $\mathrm{X}$-ray diffraction. The samples were analyzed under oxygen-free conditions, prepared in a glovebox and covered with Kapton Tape, since it is easily re-oxidized in air. ${ }^{15}$ In the solventless hydrogenation, the solid was easily isolated by evaporation of the product to dryness and the recorded $\mathrm{X}$-ray diffraction pattern was adjusted to the predicted lines of the Ru hcp structure as shown in Figure 5. It is clear that $\mathrm{RuO}_{2}$ starting material was reduced to ruthenium metallic under the hydrogenation reaction conditions $\left(4 \mathrm{~atm} \mathrm{H}_{2}\right.$ and $75^{\circ} \mathrm{C}$ ).

The WAXD pattern confirmed the complete reduction of $\mathrm{RuO}_{2}$ to $\mathrm{Ru}$ metal. Again, the simulation of Bragg reflections, using the cell parameters of the $\mathrm{Ru}(0)$, obtained by the FULLPROF code, is in good agreement with the measured data, continuous line of Figure 5. The most representative reflections to $\mathrm{Ru}(0)$ metal were indexed as hexagonal and the lattice parameters obtained were $\mathrm{a}=2.7162$ and $\mathrm{c}=4.2956$. The Bragg reflections at $38.23^{\circ}$, $42.03^{\circ}, 43.84^{\circ}, 58.11^{\circ}, 69.11^{\circ}, 78.07^{\circ}, 84.30^{\circ}$ and $85.55^{\circ}$ 


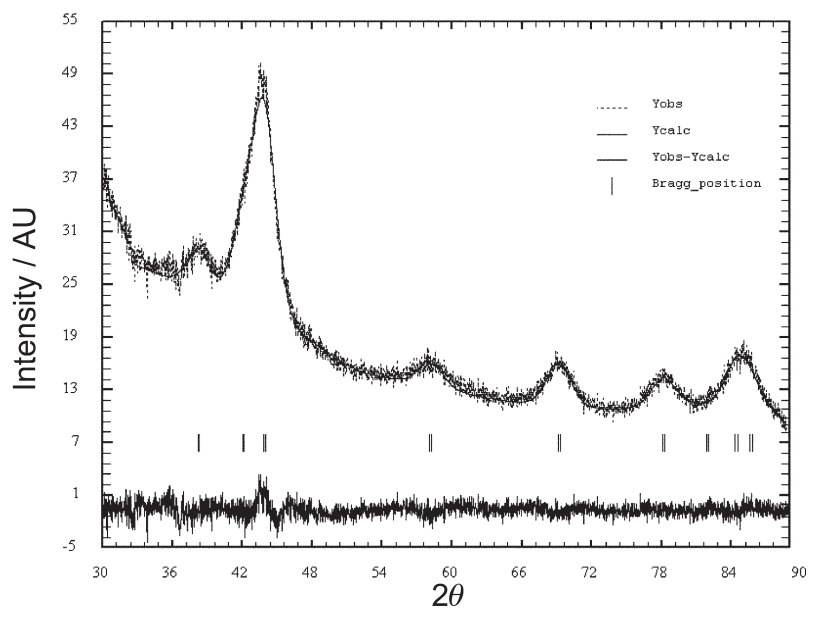

Figure 5. X-ray diffraction pattern of material isolated under argon after hydrogenation of 1-hexene by $\mathrm{RuO}_{2}$ pre-catalyst in solventless conditions.

correspond to the indexed planes of the (hcp) crystals of $\mathrm{Ru}(0)$ (100), (002), (101), (102), (110), (103), (112) and (201).

The X-ray diffraction pattern of the particles isolated from the BMI.PF 6 ionic liquid catalytic layer also showed the predicted lines of the Ru hcp structure but some $\mathrm{RuO}_{2}$ was also present since the $\mathrm{RuO}_{2}$ (211) reflection appeared at $2 \theta=53^{\circ}$. Surface re-oxidation during the isolation procedure could be the origin of such $\mathrm{RuO}_{2}$ reflection, as usually observed in $\mathrm{Ru}(0)$ colloidal samples. ${ }^{17}$ A new XRD recorded after exposure the same sample to air confirmed that the Ru metal surface is easily oxidized by $\mathrm{O}_{2}$ since the $\mathrm{Ru}(002)$ metal peak at $2 \theta=42^{\circ}$ decreased and the $\mathrm{RuO}_{2}$ reflections increased. It is noted that this re-oxidized material was still active when re-used as catalyst precursor in the hydrogenation of 1-hexene under standard conditions $\left(\mathrm{TOF}=2200 \mathrm{~h}^{-1}\right)$.

The nanoparticle size and morphology of the particles isolated after catalysis were also investigated in situ by TEM analysis carried out directly on the ionic liquid catalystcontaining phase (Figure 6). The metal-particle-size distribution was estimated from the measurement of about 200 particle diameters, assuming a spherical shape, found in an arbitrary chosen area in enlarged microphotographs. An average diameter of $2.5 \pm 0.4 \mathrm{~nm}$ was calculated in BMI.PF $_{6}$ (Figure 6) indicating that no significant changes in particles size and size distribution occurred.

Further evidences of $\mathrm{RuO}_{2}$ nanoparticles reduction to $\mathrm{Ru}(0)$ catalytic species during the hydrogenation were obtained by the $\mathrm{Hg}(0)$ and $\mathrm{CS}_{2}$ poisoning tests. ${ }^{14}$ Thus, the addition of an excess of $\operatorname{Hg}(0)$ (300 equiv.) or 0.5 equivalents of $\mathrm{CS}_{2}$ to the reaction mixture (standard hydrogenation conditions using 1-hexene as substrate) after about $50 \%$ conversion immediately suppressed the hydrogenation reaction.
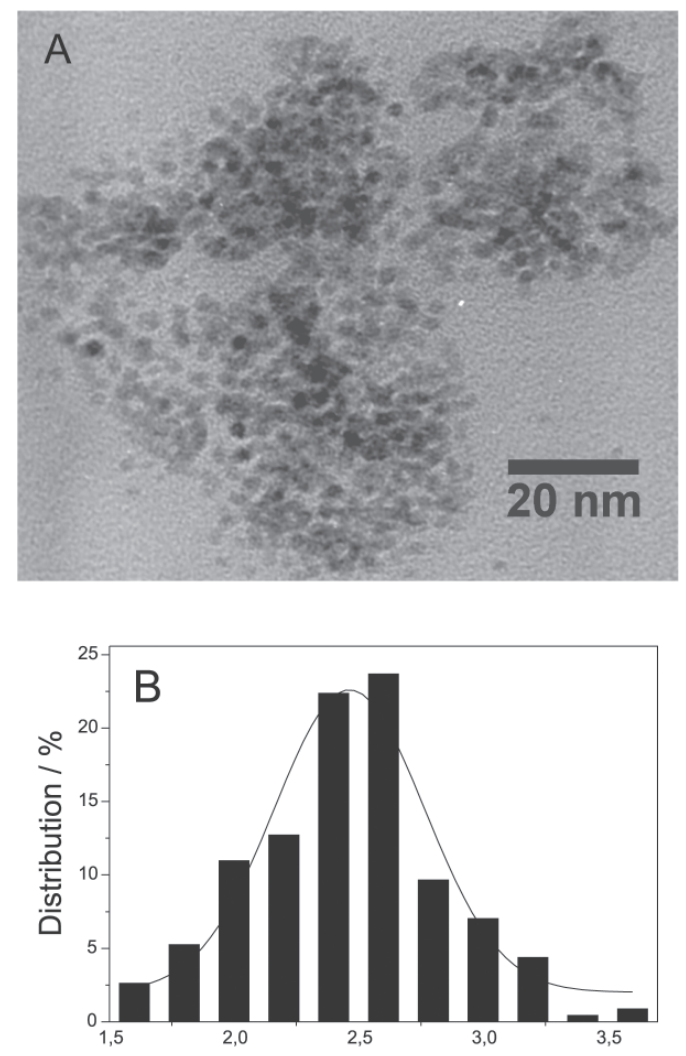

Particle size / nm

Figure 6. (A) TEM micrograph of ruthenium nanoparticles in the

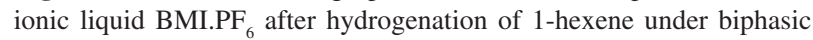
standard conditions. (B) Histogram illustrating the particle size distribution.

\section{Catalyst lifetime}

The catalyst lifetime was investigated by means of successive experiments under similar conditions to those of the standard hydrogenations, except for a catalyst to substrate molar ratio of 1/6667 for each charge. Hydrogenation of 1-hexene was selected as the model reaction. After the first cycle, the hexane product was separated by evaporation in vacuum and the isolated black material (solventless reaction) or ionic liquid catalyst containing layer (biphasic reaction) was re-used in a second run, by addition of an additional $8.4 \mathrm{~g}$ of 1-hexene (100 $\mathrm{mmol}$ ). The same procedure was repeated until a significant loss of activity was observed. In each run, 6667 maximum turnovers are possible to obtain. The recovered particles could be re-used at least 10 times in solventless conditions with 10 recycles (total turnover number $=66,600 \mathrm{~mol}$ of 1-hexene/ mol of Ru), compared to only 3 recycles (total turnover number $=20,000 \mathrm{~mol}$ of 1 -hexene/ $\mathrm{mol}$ of $\mathrm{Ru}$ ) in biphasic conditions.

Approximating the $\mathrm{Ru}(0)$ average nanoparticles $(2.5 \pm$ $0.4 \mathrm{~nm}$ ) as hexagonal-close-packed spheres it is possible to estimate, by means of a "magic numbers" approach, ${ }^{18}$ 
that roughly $35 \%$ of the Ru atoms should be on the surface. Assuming that all surface ruthenium atoms are active, it is possible to have a total turnover number for exposed $\mathrm{Ru}$ atoms of 175,000 in the solventless hydrogenation of 1hexene.

\section{Conclusions}

We have shown that near mono-dispersed $\mathrm{RuO}_{2}$ nanoparticles can be easily obtained by reaction of $\mathrm{RuCl}_{3}$ dissolved in room-temperature ionic liquids with $\mathrm{NaBH}_{4}$. These nanoparticles can be isolated as a powder, stored and used directly in solvent free heterogeneous catalysis or re-dispersed in ionic liquids for biphasic catalysis. The $\mathrm{RuO}_{2}$ are reduced by hydrogen to $\mathrm{Ru}(0)$ nanoparticles that are the catalytic active species for hydrogenation reactions. The $\mathrm{Ru}$ nanoparticles have proven to be highly active recyclable catalysts for hydrogenation of $\mathrm{C}=\mathrm{C}$ bonds under very mild reaction conditions.

\section{Acknowledgment}

We are grateful to the CENPES, CTPETRO-CNPq and FAPERGS for financial support and fellowships.

\section{References}

1. See for example: Gao, Y.; Bai, G.; Liang, Y.; Dunham, G. C.; Chambers, S. A.; J. Mater. Res. 1997, 12, 1844.

2. Jia, Q. X.; Song, S. G.; Wu, X. D.; Foltyn, S. R.; Findikoglu, A. T.; Smith, J. L.; Appl. Phys. Lett. 1996, 68, 1069; Jow, T. R.; Zheng, J. P.; J. Electrochem. Soc. 1998, 145, 49; Lin, S. M.; Wen T. C.; J. Appl. Electrochem. 1995, 25, 73.

3. Zhan, B.-Z.; White, M. A.; Sham, T.-K.; Pincock, J. A.; Doucet, R. J.; Rao, K. V. R.; Robertson, K. N.; Cameron, T. S.; J. Am. Chem. Soc. 2003, 125, 2195.

4. Armelao, L.; Barreca, D.; Moraru, B.; J. Non Crystal. Solid. 2003, 316, 364.

5. Aiken III, J. D.; Finke, R. G.; Mol. Catal. A-Chem. 1999, 145, 1; Finke R. G. In Metal Nanoparticles: Synthesis, Characterization and Applications; Feldheim, D. L.; Foss Jr., C. A., eds., Marcel Dekker: New York, 2002, chapter 2; Roucoux, A.; Schulz J.; Patin, H.; Chem. Rev. 2002, 102, 3757; Bönnemann, H.; Richards, R. M.; Eur. J. Inorg. Chem. 2001, 2455

6. Reetz, M. T.; Koch, M. G.; J. Am. Chem. Soc. 1999, 121, 7933.
7. For recent reviews see: Dupont, J.; de Souza R. F.; Suarez, P. A. Z.; Chem. Rev. 2002, 102, 3667; Olivier-Bourbigou, H.; Magna, L.; J. Mol. Catal. A-Chem. 2002, 182, 419; Dyson, P. J.; Transition Met. Chem. 2002, 27, 353; Gordon, C. M.; Appl. Catal. A-Gen. 2001, 222, 101; Sheldon, R.; Chem.Commun. 2001, 2399; Wasserscheid, P.; Keim, W.; Angew. Chem. Int. Ed. 2000, 39, 3773; Dupont, J.; Consorti, C. S.; Spencer, J.; J. Braz. Chem. Soc. 2000, 11, 337.

8. Dupont, J.; Fonseca, G. S.; Umpierre, A. P.; Fichtner P. F. P; Teixeira, S. R.; J. Am. Chem. Soc. 2002, 124, 4228; Fonseca, G. S.; Umpierre, A. P.; Fichtner, P. F. P.; Teixeira S. R.; Dupont, J.; Chem. Eur. J. 2003, 14, 3263.

9. Scheeren, C. W.; Machado, G.; Dupont, J.; Fichtner, P. F. P.; Teixeira, S. R.; Inorg. Chem. 2003, 42, 4738.

10. For the use of $\mathrm{NaBH}_{4}$ in the preparation of transition-metal nanoparticles see for example: Schulz, J.; Roucoux, A.; Patin, H.; Chem. Commun. 1999, 535; Larpent, C.; Bernard, E.; Brisse-Le Menn, F.; Patin, H.; J. Mol. Catal. A: Chem. 1997, 116, 277; Larpent, C.; Brisse-Le Menn, F.; Patin, H.; J. Mol. Cat. 1991, 65, L35.

11. Suarez, P. A. Z.; Dullius, J. E. L.; Einloft, S.; de Souza, R. F.; Dupont, J.; Polyhedron 1996, 15, 1217.

12. Sweeny, B. K.; Peters, D. G.; Electrochem. Commun. 2001, 3, 712.

13. Carbajal, J.R.; Short Reference Guide of the Program FullProf: Version 3.5, ftp://charybde.saclay.cea.fr. (2003).

14. For a detailed discussion of $\mathrm{CS}_{2}$ and $\mathrm{Hg}(0)$ poisonings tests see: Weddle, K. S.; Aiken, J. D.; Finke, R. G.; J. Am .Chem. Soc. 1998, 120, 5653; Hornstein, B. J.; Aiken, J. D.; Finke, R. G.; Inorg.Chem. 2002, 41, 1625.

15. See for example: Kikuchi, R.; Mizukami, F.; Niwa, S.; Toba, M.; Ushijima, H.; Itou, K.; Appl. Catal. A. Gen., 1997, 165, 309; Madhavaram, H.; Idriss, H.; Wendt, S.; Kim, Y. D.; Knapp, M.; Over, H.; Abmann, J.; Löffler, E.; Muhler, M.; J. Catal. 2001, 202, 296.

16. For recent examples of hydrogenation of arenes by molecular Ru catalysts see: Boxwell, C. J.; Dyson, P. J.; Ellis, D. J.; Welton, T.; J. Am. Chem. Soc. 2002, 124, 9334; Suss-Fink, G.; Faure, M.; Ward, T. R.; Angew. Chem. Int. Ed. 2002, 41, 99. For hydrogenation of arenes by supported $\mathrm{Ru}(0)$ nanoparticles see: Bianchini, C.; Dal Santo, V.; Meli, A.; Moneti, S.; Moreno, M.; Oberhauser, W.; Psaro, R.; Sordelli, L.; Vizza, F.; J. Catal. 2003, 213, 47.

17. Pelzer, K.; Vidoni, O.; Philippot, K.; Chaudret B.; Colliere, V.; Adv. Funct. Mater. 2003, 13, 118 and references therein.

18. Teo, B. K.; Zhang, H. In Metal Nanoparticles: Synthesis, Characterization and Applications, Feldheim, D. L.; Foss Jr., C. A., eds., Marcel Dekker: New York, 2002, chapter 3. 